\title{
Arte y videojuegos. Reflexiones sobre lo lúdico, el arte y la tecnología en Asturias
}

\author{
Marcelino García Sedano \\ Universidad San Francisco de Quito
}

RESUMEN:

La apertura de LABoral Centro de Arte y Creación Industrial y el lanzamiento del primer festival sobre música electrónica experimental y artes visuales LEV Festival en el año 2007, coloca a Gijón y al Principado de Asturias en los puestos de cabeza de la reflexión y exhibición de las cuestiones relacionadas con la tecnocreatividad. Semejante despliegue institucional, arranca con fuerza y con propuestas arriesgadas, entre ellas, la programación de varias grandes exposiciones sobre la relación del videojuego y la cultura en el corto periodo de dos años. Lo que podría considerarse un debate pertinente aunque arriesgado, devino en muestras históricas, discusiones importantes y la presencia no sólo de grandes artistas, programadores y diseñadores de videojuegos, sino también de grandes teóricos del medio. Este artículo pretende ahondar en la profundidad compleja del videojuego como manifestación artística y cómo esta disciplina se relacionó con los sucesos artísticos de la región asturiana.

\section{PALABRAS CLAVE:}

Nuevos Medios, videojuegos, Asturias, interactividad, arte digital.

\section{ABSTRACT:}

The opening of LABoral Centro de Arte y Creación Industrial and the launching of the first experimental electronic music festival and visual arts, LEV festival, in the year 2007, places Gijon and the Principado de Asturias in the top of the rankings in exhibition and reflexion about techno-creativity. This huge display of institutional efforts, begins with a bang and innovative proposals; among them, the programming of a couple of big exhibitions on the relationship between video games and culture in just a short two-year period. What could be considered a pertinent but risky debate, turned into historical exhibitions, important discussions and the presence of not only important artists, programmers, videogame designers, but key theorist specialized in the field, placing this way, Asturias and LABoral in the top of the world rankings on the debates about artgame. This article aims to explore the complexity of the videogame as an artistic manifestation and the ways in which it got linked to artistic events in Asturias.

\section{KEYWORDS:}

New media, videogames, Asturias, interactivity, digital art. 


\section{La importancia cultural del juego}

La importante conexión entre el juego y la cultura ha sido señalada y teorizada a mediados del siglo pasado por teóricos como John Huizinga y Roger Callois, quienes a pesar de divergir en algunos puntos de sus disertaciones, coinciden en que si bien los juegos están presentes en todas las culturas, son indudablemente constitutivos de ellas ${ }^{1}$. Callois define el juego como una actividad libre, independiente, incierta, improductiva, regulada y ficticia, rasgos que se pueden rastrear sin duda y que definen, cualquier actividad artística ${ }^{2}$.

El juego en sí, reflejo de las sociedades que los crean y disfrutan, es una herramienta que no sólo se vincula con la diversión, sino que permite alcanzar un fin concreto, en muchos casos basados en su fuerte poder de simulación que deviene en crítica. Un fin que en ocasiones empuja nuestros límites cognitivos o físicos desarrollando facetas y situaciones que pueden ser consideradas fuera de lo normal, pero cuyo proceso, interviene de manera eficiente en el desarrollo humano ${ }^{3}$. La importancia de lo lúdico queda patente en muchas teorías pedagógicas pero también en la cultura en un sentido más amplio, ya que el juego no sólo persiste en ella como un elemento más, sino que por sus características, permite analizarla y estudiarla desde una posición aventajada y mediante unos métodos específicos. La herramienta más poderosa que implica este medio es la imaginación.

Vilém Flusser, en su lucha contra el determinismo, esgrime el concepto de juego para cuestionar la linealidad causal del pensamiento histórico y lo erige como categoría de análisis social $^{4}$. Si para él, el juego es un sistema formado por elementos combinables mediante un

\footnotetext{
La obra Homo Ludens de John Huizinga, que intencionadamente inspira el título de la tercera exposición de LABoral sobre videojuego, y Man, Play and games de Roge Callois son obras capitales para entender la importancia cultural del juego.

2 CAILLOIS, Roger, Man Play and Games, University of Illinois Press, Chicago, 2001, pag 43.

3 STOCKER, Gerfried, "Playware. Jugando a explorar la nueva realidad", en Homo Ludens Ludens. Tercera entrega de la trilogía del juego, LABoral Centro de Arte y Creación Industrial, Gijón, 2008, pp. 432-433.

4 SOTO CALDERÓN, Andrea, "Juego e imaginación en Vilém Flusser”, en Flusser Studies 13, Universitá della Svizzera ialiana, 2012, Recuperado el 11/07/2016. http://www.flusserstudies.net/sites/www.flusserstudies. net/files/media/attachments/calderon-juego-imaginacion-vilem-flusser.pd
}

conjunto de reglas, el ambiente, la sociedad y la vida pueden ser entendidos metafóricamente como un conjunto de juegos y de estrategias que conforman nuestra existencia. Con esto, anuncia la evolución del Homo Faber al Homo Ludens ${ }^{5}$, un hombre, un usuario, que en esta nueva sociedad condicionada por las tecnologías informáticas y en la que la producción de imágenes es su principal y más representativa actividad, genera información a través de "jugar" con las posibilidades que esa tecnología contiene. La evolución del mito del creador al del jugador, una revolución en toda regla.

\section{Una breve historia del videojuego}

Un videojuego es un objeto cultural cuya naturaleza está compuesta de un dispositivo informático y un software que constituye el juego en sí $^{6}$. Su naturaleza multimedia y digital le relaciona directamente con el universo tecnológico y los fenómenos que se desarrollan en él, por lo tanto, la colisión entre lo humano y lo tecno científıco, deriva en una condición cibernética donde el usuario amplia su experiencia y expande su percepción y corporeidad a través de la máquina. La experiencia resultante, sumada a la fuerte carga de imaginación que aportan los juegos de la condición que sean, son de por sí interesantes desde el punto de vista cultural, pero los juegos no se han convertido en un objeto de estudio importante para las humanidades hasta que los videojuegos se convirtieron en populares y empezaron a representar una fuerte industria que generaba importantes ingresos ${ }^{7}$.

Uno de los teóricos que abogó por analizar los videojuegos como un elemento estético y de peso fue Henry Jenkins, quien aportaba así una alternativa al análisis habitual que se hacía de los mismos, siempre desde un punto de vista económico, como un problema social e incluso desde el punto de vista única y exclusivamente

FLUSSER, Vilém, Writings, University of Minnesota Press, Minneapolis, 2002, pág. 206.

6 GALLOWAY, Alexander R, "Acción del juego, cuatro momentos", en Jugabilidad: arte, videojuegos y cultura [nodo en línea]. Artnodes. N. ${ }^{\circ}$ 7. UOC, 2007. Recuperado el 19/07/2016.

http://www.uoc.edu/artnodes/7/dt/esp/galloway.pdf

AARSETH, Espen, "Investigación sobre juegos: aproximaciones metodológicas al análisis de juegos" en $J u$ gabilidad: arte, videojuegos y cultura [nodo en línea]. Artnodes. N. ${ }^{\circ}$ 7. UOC, 2007. Recuperado el 18/07/2016. http://www.uoc.edu/artnodes/7/dt/esp/aarseth.pdf 
tecnológico ${ }^{8}$. El resultado es un enfoque multidisciplinar y complejo que si bien corrobora la importancia de la disciplina, sobre todo en la relación arte-ciencia, alumbra todas las posibilidades de un medio que se inscribe dentro de los discursos basados en los nuevos medios y que no fue ignorado ni por la academia ni por las instituciones del arte ${ }^{9}$.

La conexión entre el humano y la máquina tiene su origen en la Revolución Industrial, sus avances mecánicos y sus consecuencias en cuestiones económicas, culturales y como no sociales. Por lo tanto, no es descabellado pensar que el videojuego, dependiente en un principio de interfaces que le permiten ejecutar una acción en un entorno virtual, tiene su origen en la llamada tradición del teclado, en palabras de Erkki Huhtamo, el célebre arqueólogo de los media. Esta tradición nace con la producción industrial y muy pronto se aplicaría a la construcción de diversos artefactos destinados al ocio y también al juego. Las máquinas automáticas protointeractivas ${ }^{10}$ como el kinetoscopio de Edison o el mutoscopio, las máquinas de las ferias donde se demostraba la fuerza golpeando con un martillo o disparando sobre un blanco, son ejemplos de cómo lo lúdico comienza a tecnificarse y con ello a volverse sofisticado y reflejo de los avances de una época ${ }^{11}$.

El salto definitivo a la esfera digital viene por supuesto con el desarrollo de la informática impulsado por la carrera tecnológica que protagonizaron las grandes potencias durante la Guerra

JENKINS, Henry, Games, the New Lively Art documento en línea, recuperado el 18/08/ 2016.

http://web.mit.edu/21fms/People/henry3/ GamesNewLively.html.

9 En torno a su relación con el arte, o lo que se ha venido llamando Game Art se han organizado varias exposiciones empezando con la pionera Hot Circuits: A Video Arcade, organizada por el Museum of the Moving Image de Nueva York en 1989 y comisariada por Carl Goodman quien a su vez comisarió Gameworld en marzo de 2007, la muestra con la que se inauguró LABoral y que formó parte de esa trilogía esencial del videojuego desarrollada en Gijón.

10 Aquellas máquinas que al contrario de las automáticas, demandaban del usuario una pequeña acción tal como tirar de una palanca. El resultado de dicha acción era bastante limitado ya que la máquina solía responder con una limitada acción como un bucle o la exhibición de un pequeño metraje cinematográfico.

11 HUHTAMO, Erkki, "Máquinas de diversión, máquinas de problemas", en: Jugabilidad:arte, videojuegos y cultura [nodo en línea]. Artnodes. N. ${ }^{\circ}$ 7. UOC, 2007. Recuperado el 19/08/16. http://www.uoc.edu/artnodes/7/dt/ esp/huhtamo.pdf
Fría. Como ya sabemos, esta carrera pronto tiene su eco artístico con el nacimiento del arte generativo, pero volviendo a lo anterior y aunque muchos no se ponen de acuerdo en que sea el primer videojuego de la historia, el doctor William Higinbothan físico que prestó sus servicios al Proyecto Manhattan, presentó en 1958 Tennis for Two un juego electrónico desarrollado a partir de un osciloscopio, idea seminal del juego Pong que Atari comercializaría en $1972^{12}$.

Tres años después, de la mano del MIT y comandado por Steve Russell y la Sección de investigación sobre aplicaciones no esperadas de entornos informáticos, en definitiva estudiantes que representaban la figura de primitivos hackers, desarrollan con la ayuda de una primitiva computadora PDP-1 un juego creado con entornos gráficos basados en vectores: Space War, un avance sustancial ya que Tennis for Two debía ser considerado más bien un juego electrónico porque carecía de programación. Por si fuera poco y para acrecentar la confusión en torno a los orígenes y seguir otorgando protagonismo al ámbito académico en el desarrollo de este tipo de propuestas, hay constancia de un juego que funcionaba ya con monedas llamado Galaxy War en el campus de la Universidad de Stanford y que podría tratarse del primer juego de arcade, anterior incluso al Pong ${ }^{13}$.

El paso de la academia a los hogares no se hace esperar, de un primer prototipo de dispositivo portable como es el Brown Box de Ralph Baer desarrollado en 1968, le sigue Odyssey, primera videoconsola desarrollada en 1972 por Magnavox y diseñada también por él mismo ${ }^{14}$.

A partir de este momento el videojuego se populariza y en los años ochenta con la llegada de los 8 bit y el 3D en los años noventa, sus prestaciones y las posibilidades de inmersión virtual se aumentan considerablemente y por lo tanto la capacidad de simulación que tanto servirá para el despliegue de sus posibilidades artísticas.

La interacción es cada vez más natural y como dato a tener en cuenta es que esta se hace

12 DEMARIA, Rusel y WILSON, Johnny L., High score. The illustrated history of electronic games, McGrawhill/ Osborne, New York, 2004, pp. 10 - 21.

13 HUHTAMO, Erkki, "Máquinas de diversión, máquinas de problemas", opus cit., pag 45.

14 SOLER, Pedro, "Era más que un juego", en DUARTE, Ignasi y BERNAT, Roger (ed.), Querido público. El espectador ante la participación: jugadores, usuarios, prosumers y fans, Centro Párraga, Cendeac y Eléctrica Producciones, Murcia, 2009, pág. 85. 
más física, lejos estaba aun la Wii de Nintendo, pero con el lanzamiento en 1998 de Dance Dance Revolution, el paradigma de la interfaz física llega a límites insospechados a través de un juego donde la música no es el acompañante si no el tema principal del mismo. No tardará mucho en desarrollarse Rez (2001), el primer videojuego en ser considerado un instrumento musical, basado en las teorías de Kandinsky sobre formas y colores y germen de géneros musicales electrónicos como el chiptunes y que volveremos a mencionar más adelante ${ }^{15}$.

Otra revolución absoluta fue la creación de espacios virtuales que permiten al usuario vivir en mundos paralelos y que desarrollan sociedades con la misma complejidad que la sociedad en la que vivimos. Los célebres juegos The Sims (2000) y Second Life (2003) son espacios online y multiusuario con todas las posibilidades del mundo real que nos ayudan a reflexionar acerca de la existencia y la identidad en el espacio virtual.

El espacio que posibilita estas experiencias, es lo que Javier Echeverría definió como el tercer entorno, un entorno telemático, construido a partir de las teletecnologías ${ }^{16}$ y que se suma a los dos entornos tradicionales que son el urbano y el natural. Aunque muchas de estas experiencias lúdico-tecnológicas no dependen de estar conectados, la tendencia actual es que la conexión esté presente en muchas de las acciones del ser humano por lo que en las obras artísticas de componente lúdico, llevado a cabo a partir de juegos que se practican en red como Second Life, se incide sobre todo en el apartado relacional. Este aspecto es clave ya que la experiencia virtual que propician, deriva en la recepción de un mensaje a partir de realidades tecnológicamente construidas donde la temporalidad y la instrumentación entre agentes no corporales es una característica de la inmersión facilitada por estas tecnologías. Un aspecto que genera sin dudas, nuevos ámbitos para la comunicación ${ }^{17}$.

El desarrollo de las posibilidades del juego, cada vez más complejos, reales, e interactivos,

15 Ibidem, pp. 90-91

16 Javier Echeverría define las Teletecnologías como aquellas que permiten realizar una acción en la distancia y que no sólo producen un cambio en objetos o realidades, sino que tiene la facultad de modificar las relaciones y el ámbito espacial, generando fenómenos muy particulares y propios de esta realidad que preside el intercambio de información y otros vienes en la actualidad.

17 ECHEVERRÍA, Javier. "Teletecnologías, espacios de interacción y valores”, en Teorema Vol. XVII/3, 1998, pág. 15. repercute directamente en su capacidad como herramienta artística y en el desarrollo de nuevos discursos que intensifican la disolución entre usuario y artista, la desmaterialización de la obra de arte y la democratización de la misma.

\section{Antecedentes de la relación entre arte y videojuego. Cuando el arte se anima a jugar unas partidas}

Según Tiffany Holmes, el Art Game ${ }^{18}$ está conformado por videojuegos creados o modificados por artistas y podría inscribirse dentro de una disciplina más amplia conocida como Device Art o arte de los dispositivos ${ }^{19}$. Esta plataforma característica, propone un desafío mental al usuario quien a menudo es representado en el espacio virtual a través de un icono. No es la primera vez en la historia que el arte se vincula con la producción industrial, entendiendo el videojuego como una de las más potentes industrias tecnológicas actuales. Ejemplos seminales de esta relación los tendríamos en la Bauhaus, el constructivismo, el suprematismo, el futurismo y demás corrientes vanguardistas. De igual forma, la industria del videojuego y por consiguiente el arte del videojuego, implica una integración de varias disciplinas creativas como son la música, ilustración, cine, diseño y por lo tanto también de varios géneros artísticos, casi siempre relacionados con las nuevas tecnologías, net-art, videocreación, hacktivismo, perfomance, etc.

El juego ha merecido un interés histórico para la creación de vanguardia por diversas razones de peso, recordemos el interesante Chess de John Cage con Marcel Duchamp quien mantenía que sin espectador no hay obra. Esta afirmación, aplicada al Art Game o a cualquier disciplina del New Media Art, se traduce en que sin jugador, no hay juego y por lo tanto arte ${ }^{20}$. El surrealismo y

18 Prefiero mantener el nombre en inglés frente al término castellano más impreciso. Hay, según varios autores, diferencias entre Art Game y Game Art. Resumiendo las mismas, el Art Game sería el arte llevado a cabo mediante videojuegos mientras que el Game Art, a pesar de tener alusión a los mismos, no tiene porque contar con ellos como herramienta expresiva.

19 HOLMES, Tiffany, "Arcade Classics Spawn Art? Current Trends in the Art Game Genre", en The Digital Arts Conference (DAC), Melbourne Australia, 2003. Recuperado el 20/08/2016. http://hypertext.rmit.edu.au/ dac/papers/Holmes.pdf.

20 ESCRIBANO, Flavio, "FULL HD: Ahmadineyad y Obama se pican al Counter Strike", en Arcadia. Juegos desde una 
el dadaísmo incorporaron a sus discursos alusiones al juego y en ocasiones establecieron obras donde el espectador debía jugar, pero no es hasta el surgimiento del happenning y la incorporación del concepto de interactividad cuando la palabra jugar se puede aplicar a las acciones de público y artistas. El happening como un intento de borrar las barreras entre ambos, impulsaba la unión de arte y vida. El movimiento Fluxus, a través del Manifesto on Art Amusement de George Maciunas abogaba también por el juego, la diversión, la simplicidad de la obra y la carencia del valor mercantil o institucional rompiendo con el concepto elitista de arte ${ }^{21}$.

No hay duda de que el videojuego es un arte inmersivo, un arte donde el jugador despliega habilidades e interpreta personajes, es por tanto una disciplina performativa aunque sea el espectador o el usuario quien en la mayoría de las ocasiones se encarga de realizar la acción significativa $^{22}$. Para Alexander Galloway los videojuegos son acciones y por lo tanto la obra en sí es esa acción, sin ella el videojuego sólo es un loop que se ejecuta automáticamente en un dispositivo tecnológico ${ }^{23}$.

Dentro de esta distinción, habría dos tipos de acciones, las de la máquina y las del usuario y si bien la conducta es jugar, lo interesante es la mezcla de ambas. Cuando la máquina y el usuario trabajan juntos en una relación cibernética el hombre deviene en cyborg y se vincula a una ciudadanía de mundos virtuales creados artificialmente y a la creación de realidades sociales paralelas, simulación y copia de las originales o transformación de las mismas ${ }^{24}$. Por lo tanto el cyborg construye y participa de una realidad simulada, copia metafórica y poética de la real generando nuevos e interesantes fenómenos propios de la cultura cyborg. Sirva de ejemplo el proyecto artístico denominado Corpus Simsi (2002-2004), basado en los Sims ${ }^{25}$. En él, la au-

cultura de la innovación. Mediateca Expandida, LABoral Centro de Arte y Creación Industrial, 2009, pág. 84.

21 BAIGORRI, Laura, "I Will Not Make Any More Boring Art. Subvirtiendo elitismo y banalidad", en Homo Ludens Ludens, Tercera entrega de la trilogía del juego, LABoral Centro de Arte y Creación Industrial, Gijón 2008, pág. 21.

22 JENKINS, Henry: Games, the New Lively Art opus cit.

23 GALLOWAY, Alexander R, "Acción del juego, cuatro momentos", opus cit., pág. 24.

24 HARAWAY, Donna J, Simians, Cyborgs, and Women: The Reinvention of Nature, Routledge, Nueva York, 1991, pp. 149-183.

25 SOLER, Pedro, “Era más que un juego”, opus cit., pág. 99. tora Chloe Dalaume utiliza el espacio virtual del juego para poner en contraposición el mundo real y el simulado a través de diversas acciones artísticas que ejecuta a través de un avatar, que no es ni más ni menos que la representación gráfica en un juego de un usuario, un cibercuerpo que se corresponde con una ciberidentidad, no siempre relacionada con la del jugador sino en ocasiones inventada, mejorada o simulada.

Otra definición actual del usuario de las teletecnologias, es la de hibronauta, término acuñado por Laura Beloff en plena época de conexiones y dispositivos protésicos tecnológicos para explicar la influencia de éstas en el ser humano. Este concepto permite juzgar al usuario y al entorno como un conjunto dentro de un espacio híbrido en el que se generan una serie de prácticas sociales, entre ellas la creación artística y que a pesar de tener un origen tecnológico, no comparten todas las características de la mayoría de los fenómenos derivados de las tecnologías portátiles y desarrollan aspectos propios $^{26}$. Esta dimensión social, particular, virtual e interactiva es ni más ni menos que una metáfora de la sociedad real a través de una estructura jugable ${ }^{27}$. El hibronauta como usuario de los videojuegos o de los art games, aborda desde esa plataforma los problemas de esta sociedad, centrando su atención en asuntos de género, sexualidad, migratorios, políticos, económicos y laborales entre otros con una gran y especial presencia del ciberfeminismo.

\section{Metodología y praxis del videojuego como herramienta artística. Las reglas del juego.}

Interacción y acción son dos palabras con hegemonía en el entorno digital, pero hay una palabra que proviene del uso más corriente de los videojuegos, esta es jugabilidad y define la facilidad del usuario para explorar las posibilidades que ofrece la simulación del mundo que plantea el juego. Al contrario de lo que muchos creen, no depende tanto del realismo del entorno virtual del juego como de la facilidad y libertad para poder navegar por él, facilitando la experiencia inmersiva por parte del jugador.

\footnotetext{
${ }^{26}$ BELOFF, Laura, "The Curious Apparel: Wearables and The Hybronaut" en Intelligent Agent, issue 8.1. Recuperado el 08/09/2016. http://www.intelligentagent.com/archive/ia8.1lastfinal.pdf

27 GALLOWAY, Alexander R, "Acción del juego, cuatro momentos”, opus cit., pág. 32.
} 
Ese mundo y esas experiencias posibles han resultado muy interesantes para muchos artistas que han visto en la fórmula del videojuego, la herramienta expresiva perfecta ${ }^{28}$. Este interés viene no sólo por esta capacidad simuladora sino también por las posibilidades de crear proyectos colaborativos con otros usuarios y espacios que no siempre son los tradicionales en el mundo del arte y que explotan al igual que el hackitivismo, las posibilidades de lo virtual. La colaboración entre técnicos, artistas y usuarios, consolida comunidades poderosas que funcionan al margen de los circuitos tradicionales del arte y de la industria con un intercambio de información muy interesante y democrática, basada en la independencia y desde una actitud totalmente opuesta a la elaboración de juegos comerciales $^{29}$.

Esta esfera de juegos independientes creados con intenciones artísticas tiene su origen en 2002 en colectivos como Jodi, Glaznost y Retroyou en una mezcla entre apropiación y piratería que interviene juegos ya existentes, alterando su estructura o funcionamiento $\mathrm{y}$ creando nuevas piezas y significados no carentes de ironía ${ }^{30}$.

El Modding, así se llama la alteración, aplica no solo al software sino también al hardware mediante intervenciones y desarrollos de nuevos dispositivos. Es común el uso y la creación de nuevos códigos abiertos al público u Open Source en defensa de la libertad del usuario y el creador, filosofía de partida de este tipo de arte y alegoría de las posibilidades del mismo. Anecdóticamente en el congreso de videojuegos de Atenas de 2006, se encumbró Realtime $3 D$, como la tecnología creativa más relevante después de la pintura. El poder de este software que hace que la creación de un videojuego esté al alcance de cualquiera es infinito ya que al ser una herramienta tan democrática e intuitiva, puede generar infinidad de discursos diferentes ${ }^{31}$.

${ }^{28}$ ALSINA, Pau, "Presentación", en: Jugabilidad:arte, videojuegos y cultura [nodo en línea]. Artnodes. N. ${ }^{\circ} 7$. UOC, 2007. Recuperado el 12/08/20116.

http://www.uoc.edu/artnodes/7/dt/esp/jugabilidad.pdf

29 BITTANTIAND, Matteo, Game Art, (This is not) A Manifesto(This is) A Disclaimer, documento en línea. Recuperado el 12/09/2016.

http://wenku.baidu.com/view/f741f9e9998fcc22b cd10d63.html

30 SOLER, Pedro, “Era más que un juego”, opus cit., pág. 92.

31 Realtime 3D es una herramienta que permite generar y modificar figuras 3D en tiempo real, su uso no sólo se
5. Art Game en Asturias. Creación industrial, hacktivismo, virtualidad, historia y teoría del videojuego en LABoral Centro de Arte y Creación Industrial.

Durante los dos primeros años de vida de LABoral Centro de Arte y Creación Industrial hubo una especial atención al videojuego como elemento artístico y cultural. Este énfasis se materializó en varias exposiciones, "Gameworld" una de las inaugurales del Centro y llevada a cabo entre el 30 de marzo y el 30 de junio de 2007, "Playware" del 21 de septiembre de 2007 al 21 de marzo de 2008 y "Homo Ludens Ludens" celebrada del 18 de abril al 22 de septiembre de 2008, cerrando la llamada trilogía del juego. Completan las actividades la inauguración del espacio Mediateca Expandida, su primera publicación y la muestra "Arcadia", celebrada del 2 de octubre al 7 de diciembre de 2009 y dedicada a los aspectos más experimentales del videojuego.

Comencemos por "Gameworld", la exposición se estructuró en tres bloques, o argumentos expositivos: "El canon del juego digital", una selección de diez de los grandes juegos más significativos de la industria entre los que se incluyen los imprescindibles Spacewar del MIT y otros míticos como Zork I (1980), SimCity, Tetris, Doom, pieza precursora de los juegos de disparos en primera persona, etc ${ }^{32}$. Esta sección fue comisariada por un grupo de cinco especialistas en historia y diseño de los juegos y presentada con anterioridad días antes en San Francisco en la Game Developers Conference ${ }^{33}$. Todos estos ejemplos fueron un éxito para la industria y un ejemplo de cómo estas plataformas han evolucionado y han abierto nuevas posibilidades de experiencias expandiendo históricamente el concepto de jugabilidad.

El segundo conjunto, "Juegos Recodificados”, está más relacionado con la expansión o el despliegue de las cualidades artísticas del vi-

aplica a crear videojuegos sino a cualquier necesidad de generar gráficos para computadora.

32 Los diez videojuegos que conformaron el canon fueron: Spacewar!, Star Raiders, Zork I, SimCity, Civilization I/ II, Super Mario 3, Doom, Sensible World of Soccer, , Warcraft (Series) y Blizzard Entertainment.

33 La recopilación fue un encargo de la Librería del Congreso de Estados Unidos al conservador de "Las colecciones de historia de la ciencia y la Tecnología" de la Universidad de Stanford, Henry Lowood, quien junto a cuatro especialistas impulsaron que los videojuegos se conservaran desde el punto de vista historiográfico. 
deojuego a través de la modificación de juegos preexistentes para elaborar nuevos discursos o experiencias. El Modding expande los límites de la jugabilidad y la experiencia, rediseñando por completo tanto el software como el hardware. La modificación de juegos a través de la computadora deviene en varias posibilidades o subgéneros del Art Game, considerado en sí mismo como un subgénero del arte generativo. Estos subgéneros tendrán su presencia en esta muestra por ejemplo el Machimina, disciplina que parte de la utilización de contenido preexistente en los juegos, ordenándolo y utilizándolo para crear nuevos productos como cine, cortometrajes, etc. Anisandbox (2007) de Friedrich Kircchner parte de una aplicación de código abierto y uso libre, Movie Sandbox, para crear videos en tiempo real desde un videojuego, en concreto desde Unreal Tournament. El proceso de creación es múltiple y simultáneo ya que mientras unos usuarios mueven su cámara dentro del juego, otros acompañan musicalmente las imágenes capturadas.

Otro proyecto en el que se elabora una película de terror de o ficción a partir de otros videojuegos, es Sheik Attack (1999) de Eddo Stern que toma imágenes de juegos como Nuclear Strike, Red Alert y Settlers III para narrar la historia del sionismo criticando su fuerte militarización.

Sonichima, es una disciplina destinada a producir música a través de elementos sonoros presentes en los videojuegos como su banda sonora, efectos de sonido o considerándolos un instrumento musical en sí. La música chiptunes u 8 bit que se ejecuta a partir plataformas portátiles como Gameboy y que ya es considerado todo un género de música electrónica, sería un ejemplo de esto. Dentro de las actividades específicas de la muestra entre las cuales se programaron cuatro talleres, destaca uno dedicado a la producción de este tipo de música, basada en las bandas sonoras y los sonidos que acompañaban a los primeros videojuegos. La herramienta o instrumento elegido es la célebre videoconsola portátil Gameboy ${ }^{34}$.

El punto fuerte de la modificación de juegos se manifiesta en algunas de las obras seleccionadas que profundizan o simplemente se recrean en la inmersión y jugabilidad de las

34 Con un profesorado compuesto por artistas del género internacionales como Haeyoung Kim, Chris Burke, Rabato, Yes Robot y el dúo Enter, las actividades concluyeron con un directo entre alumnos y profesores. mismas y en el cambio de percepción del espacio, la identidad y demás cosas sólo posibles en un entorno virtual. Obras como 2nd Person Shooter (2006-07) de Julian Oliver ahondan en la transposición de cuerpos virtuales cuando un usuario, juega desde la perspectiva de otro en un espacio sin referencias y enfrentados a sensaciones sólo posibles en ese juego. El hombre cyborg, habita el espacio virtual y los esquemas de la existencia terrenal no tienen cabida en éste. Siguiendo en el análisis de las experiencias sensoriales a través de dispositivos Darkgame (2007) de Eddo Stern experimenta con la privación sensorial y cómo esta influye en el habitar el espacio cibernético, dos jugadores, uno sin vista y otro que es golpeado continuamente se mueven por un mundo virtual.

Esta compilación de actitudes de creación libre, espíritu hacker y apropiacionista, plantean paradigmas sobre el poder y el control, el capitalismo, el género en la sociedad cibernética o la obsolescencia del cuerpo y la transformación de la identidad bajo la perspectiva del humano cyborg. La sombra de la política se cierne sobre obras como Invaders!(2001), un juego recodificado a partir del clásico Space Invaders por Douglas Edric Stanley y que tiene como inspiración los atentados del 11 de septiembre de 2001. La dinámica del juego es muy sencilla e invita al espectador, usuario o jugador a disparar a naves enemigas que vuelan sobre la silueta del World Trade Center. Las distintas versiones del juego permiten incluso disparar sólo con los dedos, en un ejemplo del cuerpo humano como interfaz biológico.

Las referencias a las situaciones políticas y la utilización del videojuego para denunciar situaciones injustas como la guerra, la migración, las fronteras y un largo etcétera tiene su espacio en la tercera sección llamada "Juegos serios" cuyas obras despliegan la representación alegórica de la intervención política en base a una crítica y a una actitud, de nuevo, marcadamente hacktivista ${ }^{35}$. Obras polémicas como Super Columbine Massacre RPG (2006) de Dann y Ledonne donde se plantea que el jugador sustituya la identidad de los dos autores de la conocida masacre; Dead in Iraq (2006) de Joseph Delappe, una performance agresiva donde el autor accede al juego online proporcionado de manera propagandística por las

\footnotetext{
35 HOLMES, Tiffany, "Arcade Classics Spawn Art? Current
} Trends in the Art Game Genre”, opus cit., pág. 98. 
fuerzas armadas de Estados Unidos mientras que utiliza su chat para escribir los nombres de los soldados muertos en Iraq. Son obras que critican el posicionamiento ideológico de esta gran potencia y las consecuencias de sus políticas bélicas o armamentísticas.

A través del desarrollo de tecnologías de geolocalización en plataformas digitales, podemos analizar cual es nuestra manera de habitar el espacio urbano desde el entorno virtual y como esta puede ser representada ${ }^{36}$. El videojuego puede ser una herramienta perfecta para analizar este hecho y Bordergames es una iniciativa que, además de dar nombre a un taller celebrado en el mes de julio y en el contexto de esta exposición, transforma este medio en una plataforma de performance crítica. De estos talleres donde se forma al público en la utilización de herramientas de modelado 2D, la Fiambrera Obrera, colectivo madrileño, elabora un juego en espacios urbanos donde la presencia de jóvenes emigrantes es significativa y plasma sus problemáticas en ellos de tal manera que el usuario pueda conocer y experimentar en primera persona estas situaciones. Estos jóvenes, sin acceso en ocasiones a esas tecnologías son los que fabrican y elaboran el juego en un proceso colaborativo con los artistas.

"Playware. El mundo de los videojuegos: pack de expansión" fue la segunda muestra dedicada a explorar el nexo entre el videojuego y el arte interactivo, algo que completaba a "Gameworld", ocupada en mostrar las posibilidades expresivas y críticas de este medio y no tanto las consecuencias de las tecnologías digitales en la sociedad y en la cultura ${ }^{37}$. Según Gerfried Stocker, director de Ars Electrónica, entidad que comisaría la muestra junto el Museum of Moving Image de New York, el enfoque ya no era sólo narrativo sino lúdico. "Playware" investiga sobre abstracción visual, la interactividad a través del desarrollo de interfaces y en definitiva las posibilidades creativas del videojuego, industria que a su vez demanda el desarrollo de la tecnología más potente y avanzada. Como expresa Goodman, co-comisario de la muestra, muchas de las instalaciones y obras que se pudieron encontrar en esta exposición fueron desarrolladas por personas y colectivi-

\footnotetext{
SOLER, Pedro, "Era más que un juego", opus cit., pág. 96 STOCKER, G., "Playware - Jugando a explorar la nueva realidad", en Homo Ludens Ludens, Tercera entrega de la trilogía del juego, LABoral centro de Arte y Creación Industrial, Gijón 2008, pág. 432.
}

dades relacionadas con las instituciones más importantes que investigan los nuevos medios como Interval Research de Palo Alto, Futurelab de Ars electrónica e incluso el MIT $^{38}$. El videojuego y el arte interactivo creado a partir de esta plataforma, son motores muy importantes para la investigación tecnológica y precisamente su enfoque creativo e independiente, le permite experimentar de manera más libre con nuevas herramientas y usos de tecnologías.

Dentro de la muestra encontramos más videojuegos creados expresamente con un sentido artístico como Electroplancton (2005) de Toshio Iwai, creador del Tenori on ${ }^{39}$ y producido por Nintendo. La plataforma permite crear patrones musicales a través de la interacción táctil con una pantalla donde flotan representaciones de plancton. Vuelve la relación del arte con la música que tanto sedujo a las vanguardias artísticas, vuelve la opción de convertir o desarrollar plataformas que se conviertan en sí mismas en instrumentos y se acrecienta el concepto de democratizar la música a través de soportes más intuitivos cercanos a la experiencia "do it yourself". Hablando de las vanguardias y su legado, $R E Z$ es un juego basado en las asociaciones sinestésicas y fundamentado en las teorías de Kandinsky de la relación entre colores y sonidos, Se ejecuta a partir de una Playstation, dispositivo doméstico que conduce al usuario a una experiencia global cercana a la psicodelia sin necesidad de una tecnología muy exclusiva. Otra alusión a movimientos artísticos pasados, en concreto al Action Painting era Mono (2007), obra de varios autores y que asocia la figura del shooter basado en los videojuegos clásicos de lucha espacial, con la experiencia de disparar color donde el resultado es una pantalla llena de burbujas de colores que explotan manchando toda la superficie y generando composiciones visuales únicas que recuerdan en ocasiones a cuadros de Jackson Pollock.

Las instalaciones son sin duda otro de los géneros o formatos más habituales y especta-

38 GOODMAN, C., "Playware - Un pack en expansión para Gameworld", en Homo Ludens Ludens, Tercera entrega de la trilogía del juego, LABoral centro de Arte y Creación Industrial, Gijón, 2008, pág. 434.

39 El Tenori On fue un instrumento musical interactivo producido conjuntamente por el autor y Yamaha y presentado en SIGGRAPH en el año 2005. El dispositivo se ejecuta de manera intuitiva y tiene una importante componente visual ya que se toca a través de la activación lumínica de 256 ledes. 
culares dentro del arte basado en los videojuegos, "Playware", interesada en mostrar el desarrollo de interfaces y experiencias asociadas al uso de las mismas, contó con una buena representación de lo que se denominó bajo esta modalidad, por motivos comisariales, instalaciones multijugador. De la interactividad e interacción en dos ciudades distintas que ofrecía Bump (1999) de Assocreation, dos plataformas en dos ciudades distintas e interconectadas vía internet, a la interrelación física entre dos personas de Freqtric Project (2007) que pone en entredicho la falta de comunicación corporal en la era de la comunicación digital. Este proyecto de Tetsuaki Baba y la Kyushu Graduate School of Design, se basa en el desarrollo de una interfaz de contacto epidérmico basado en la emisión de energía eléctrica a través de la piel. Puede utilizarse como instrumento musical o simplemente para comunicarse. El valor del mismo es que integra simbióticamente dos sistemas, el biológico y el digital o informático.

"Homo Ludens Ludens", que toma su nombre del célebre libro de John Huizinga, sería la tercera de las grandes exposiciones que se llevaron a cabo en LABoral y que en este caso concreto analizó la inserción del videojuego en nuestras vidas cotidianas y cómo modifica en mayor o menor medida a la sociedad. De hecho, el subtítulo de esta muestra fue "Situando el juego en la sociedad y cultura contemporáneas".

Entre las obras que se encontraron merece especial atención aquellas que por su temática concuerdan con lo que en la primera muestra fueron considerados "juegos serios", en este caso encontramos Schengen Information System, Version 1.0.3 (2004) del serbio Vladan Joler donde el jugador debe escoger un posición ideológica frente a conflictos reales a través de una estructura clásica de videojuego bélico. Este tipo de juegos ve criticada a través de esta simulación, su posicionamiento ideológico y moral, ya que en muchos casos son considerados productos propagandísticos y pro violencia. De igual forma, UnderSiege (2004) es otro juego de acción en primera persona que basada en los hechos recientes de la primera Intifada Palestina reproduce situaciones reales vividas en este espacio ${ }^{40}$. Radwan Kasmiya, el autor, no defıne sus juegos como juegos políticos ya que

40 La segunda intifada tuvo lugar entre el año 1999 al 2002. prefiere calificarlos como históricos, sociales o reality games ${ }^{41}$.

El espacio diegético, según Galloway, es aquel espacio figurado donde tiene lugar aquello que se considera la acción del juego ${ }^{42}$. Basar la historia del juego, es decir ese espacio, en hechos reales, es un recurso habitual que permite que a través de la vivencia de esos hechos de forma virtual, el jugador pueda reflexionar en mayor o menor medida sobre el alcance y gravedad de los mismos. Por eso, Matari 69200 (2005) en un hábil juego de palabras que une Atari con el número de muertes política en el Perú de los años ochenta, lanza una crítica sobre los hechos históricos de ese periodo.

Críticas a la economía mundial, referencias de nuevo a masacres, la inmigración y demás temas completan esta selección de crítica social. No obstante un apartado muy importante son aquellas obras que hacen énfasis en las cuestiones de jugabilidad, de interacción con una base más empírica y que revela la importancia de la experiencia en el moderno acto de jugar.

SweetPads (2004) de France Cadet desarrolla una interfaz de juego a modo de Joysticks donde el acto de jugar se convierte en una acción suave y premeditadamente sensible, aportando una práctica sin duda nueva al manejo de este tipo de dispositivos. Stiff People's League (2007), desarrollado por el Media Lab del MIT junto a Drew Harry, Dietmar Offenhuber y Orkan Telhan, plantea una revisión de un juego clásico como el futbolín a través del enfrentamiento del mundo físico y el digital donde unos jugadores virtuales se complementan con unos jugadores físicos en una experiencia híbrida y desconcertante. Echeverría había apuntado que en la inmersión dentro del espacio electrónico, las herramientas que la facilitan, no sólo nos conectan con otros usuarios, si no con objetos y personas artificiales, tecnopersonas, una entidad sólo posible en estos lugares y fruto de la creación de programadores, pero que en el caso de esta obra, sirven para poder materializar la acción propuesta en ella ${ }^{43}$.

Para cerrar este breve repaso, especial mención el proyecto del artista asturiano Ro-

\footnotetext{
${ }_{41}$ Entrevista al autor en BOSCO, Roberta, "Videojuegos de la Intifada”, en Babelia, El País, 26 de abril de 2008.

42 GALLOWAY, Alexander R, "Acción del juego, cuatro momentos”, opus cit., pp. 26, 27.

43 ECHEVERRÍA, Javier. Entre cavernas. De Platón al cerebro, pasando por internet. Triacastela, Madrid, 2013. pág. 20
} 
mán Torre en una versión seminal de LifeFloor (2008), una instalación que rinde homenaje al "juego de la vida" del matemático británico John Horton Cornway. Un autómata celular que hizo su aparición en 1970 y que sintetiza que todo lo que se puede computar algorítmicamente, como en la máquina de Turing en la que se basa, se puede representar en este juego. Un algoritmo que evoluciona como un sistema vivo en emergencia y auto organizado y que tuvo gran trascendencia no sólo para los amantes de la programación sino también para muchos razonamientos filosóficos que intentaban sintetizar el funcionamiento de los sistemas vivos ${ }^{44}$.

Lo que sí dejó un gran legado para la historia fue el "Simposio Internacional Homo Ludens Ludens" que se realizó en colaboración con el Planetary Collegium que dirige Roy Ascott quien participó con una ponencia en dicho simposio y un artículo en el catálogo de la muestra. El catálogo unificaba las tres muestras anteriores e incluía artículos resultantes de este encuentro llevado a cabo el 19 y 20 de abril de 2008, reflexiones profundas sobre la importancia de esta disciplina artística de la mano de una extensa nómina de creadores, comisarios, críticos y académicos internacionales de primera clase ${ }^{45}$.

La última incursión significativa en el mundo del videojuego con aplicaciones artísticas fue la primera actividad de Mediateca Expandida que publica el primer número de la revista con el mismo nombre e inaugura, con muestra incluida, este nuevo espacio multidimensional en la LABoral dedicado a la investigación, experimentación y a la exhibición de las conclusiones y obras que surgen en este contexto ${ }^{46}$. La exposición “Arcadia”, una reflexión capitaneada por José Luís de Vicente, continua en la

$44 \quad$ Para más información y ver de qué se trata el juego realmente: https://es.wikipedia.org/wiki/Juego_de_la_ vida

45 Laura Baigorri, comisaria de nuevos medios y profesora de Bellas Artes de la Universidad de Barcelona, Guto Nóbregha en nómina en el Planetary College junto a Luis Miguel Girao, José Luís de Vicente periodista y comisario entre otros, aportan interesantes reflexiones y un corpus de textos muy interesante en el catálogo de la muestra.

46 La primera edición de la revista contó con 5000 ejemplares además de su disponibilidad gratuita en la red, http://www.laboralcentrodearte.org/es/iles/2009/exposiciones/mediateca.arcadia-doc/mediatecaexpandidaarcadia.pdf/view. línea de las muestras anteriores pero desde una perspectiva si cabe más flexible y experimental, atendiendo a las líneas de investigación que plantea el panorama lúdico. Al final, tenemos una serie de obras, más de treinta, que han sido desarrolladas en su mayoría entre 2007 y 2009. En ellos volvemos a encontrar diseño de nuevos juegos e interfaces, "juegos serios" y planteamientos acerca de la experiencia a partir del entorno virtual con una mayor presencia de juegos desarrollados por grandes ejemplos de la industria del entretenimiento.

\section{Conclusión}

La vinculación de LABoral con este tipo de disciplina artística puede ser considerada una de las de mayor importancia a nivel internacional, no sólo desde el punto de vista de la difusión y producción de obras, sino también como punto de debate sobre la situación de las mismas. El comienzo fuerte y arriesgado de esta institución se ratifica en apuestas como éstas que si bien contaron con piezas, teóricos y la colaboración con instituciones de primer orden, resultaron algo confusas en sus objetivos iniciales y si cabe, algo repetitivas. Lejos de ser un defecto, esa falta de homogeneidad conceptual hizo que al menos, durante un espacio más o menos largo de tiempo, la región se convirtiera en un lugar de referencia sobre la confluencia entre lo artístico, lo lúdico y las nuevas tecnologías, además de poder contar con la presencia de las principales figuras al respecto vinculadas al proyecto LABoral. Acceder a las principales discusiones sobre Art Game estuvo en mano de los asturianos, tanto artistas, académicos y público.

La eficacia y alcance de las mismas a nivel de inserción en la sociedad asturiana es algo digno de otro debate ya que si de algo se acusó a LABoral, fue de ser un lugar aislado, elitista y con poco alcance social sobre todo a nivel local. Cierto o no, para la historia del arte quedan estas muestras y su calidad indiscutible. El tiempo dirá si en un futuro Gijón y Asturias continúan en la misma línea e incluso definirá la evolución de la disciplina, pero cuando ésta estaba en pleno auge, tuvo su espacio destacado en la región. 